\title{
Wittig Like Methylenation of Aldehydes in a Microflow System: Selective Methylenation by Differential of Plural Reactions
}

\author{
Yoshiaki Takada and Seijiro Matsubara* \\ Department of Material Chemistry, Graduate School of Engineering, Kyoto University, \\ Kyoudai-katsura, Nishikyo-ku, Kyoto 615-8510
}

(Received January 14, 2011; CL-110037; E-mail: matsubar@orgrxn.mbox.media.kyoto-u.ac.jp)

Methylenation of aldehydes with bis(iodozincio)methane was performed using a microflow system. Treatment of a dialdehyde with bis(iodozincio)methane in the system can divide two methylenation reactions and realize selective transformation.

Recently, flow reactions have been intensively studied from the viewpoint of productivity and sustainable chemistry. ${ }^{1}$ In addition, space integration of chemical reactions has been also realized by microflow systems. ${ }^{2}$ We have focused on the Wittig like methylenation of aldehydes with bis(iodozincio)methane (1) as a candidate for flow reaction (Scheme 1). ${ }^{3}$ Generally, methylenation of aldehydes is performed with a typical Wittig reagent, methylenetriphenylphosphorane. ${ }^{4}$ When this reaction is attempted in a flow reactor, ${ }^{5}$ formation of insoluble phosphine oxide may cause difficulty in the flow. As methylenation of an aldehyde with 1 does not form any insoluble salts during the reaction, it may not encountor any obstacle in practical operation. In addition, a flow reaction can divide plural reactions as well as the integration of a single reaction. Along this line, we also expected selective methylenation in substrates carrying plural formyl groups.

When benzaldehyde (2a, $1.0 \mathrm{mmol})$ was treated with bis(iodozincio)methane $(1.1 \mathrm{mmol})$ in $\mathrm{THF}$ at $25^{\circ} \mathrm{C}$ in a reaction vessel for $0.5 \mathrm{~h}$, styrene (3a) was obtained in $83 \%$ yield (in $87 \%$ at $\left.60{ }^{\circ} \mathrm{C}\right) .{ }^{3}$ As shown in Figure 1, we examined the reaction in a microflow system consisting of two T-shaped micromixers, M1 and M2, and two microtube reactors, $\mathbf{R} 1$ and $\mathbf{R 2}$. The yield of $\mathbf{3}$

$$
\mathrm{R} \underset{2}{\stackrel{\mathrm{O}}{\mathrm{O}_{\mathrm{H}}}}+\mathrm{CH}_{2}(\mathrm{Znl})_{2} \underset{\mathbf{T H F}}{\longrightarrow} \underset{\mathbf{R}}{\stackrel{\mathrm{CH}_{\mathrm{H}}}{\mathrm{CH}_{2}}}+\mathrm{IZnOZnl}
$$

Scheme 1. Methylenation of aldehydes with bis(iodozincio)methane (1).

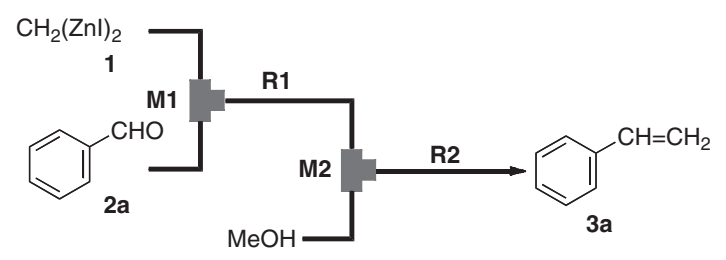

Figure 1. Microflow system for methylenation: T-shaped micromixer: M1 (inner diameter: $250 \mu \mathrm{m}$ ) and M2 (inner diameter: $250 \mu \mathrm{m})$, microtube reactor: $\mathbf{R} 1 \quad(\phi=1000 \mu \mathrm{m}$, length $=10 \mathrm{~m}), \mathbf{R 2}(\phi=1000 \mu \mathrm{m}$, length $=2 \mathrm{~m})$, a solution of 1: $0.38 \mathrm{M}$ in THF, a solution of 2: $0.35 \mathrm{M}$ in THF, methanol $\left(3.0 \mathrm{~mL} \mathrm{~min}^{-1}\right)$. was determined by changing the residence time in $\mathbf{R} \mathbf{1}$ and the temperature of the ethylene glycol bath in the microflow system. The residence time was adjusted by changing the flow rate in $10 \mathrm{~m} \mathrm{R1}$ (Figure 2). In M2, quenching reagent $\mathrm{MeOH}$ for unreacted 1 was injected.

As shown in Figure 2, the highest yield $89 \%$ was observed at the intersection of $3 \mathrm{~min}$ (residence time in R1) and $60^{\circ} \mathrm{C}$ (bath temperature). Figure 2 also shows that the methylenation of aldehyde is fast enough to give the alkene in over $70 \%$ yield within 1 min residence time. Under these conditions, using the flow reactor, other aldehydes were also converted into the corresponding alkenes as shown in Figure 3. Benzaldehyde derivatives $\mathbf{2 b}-\mathbf{2 d}$ carrying various substituents were trans-

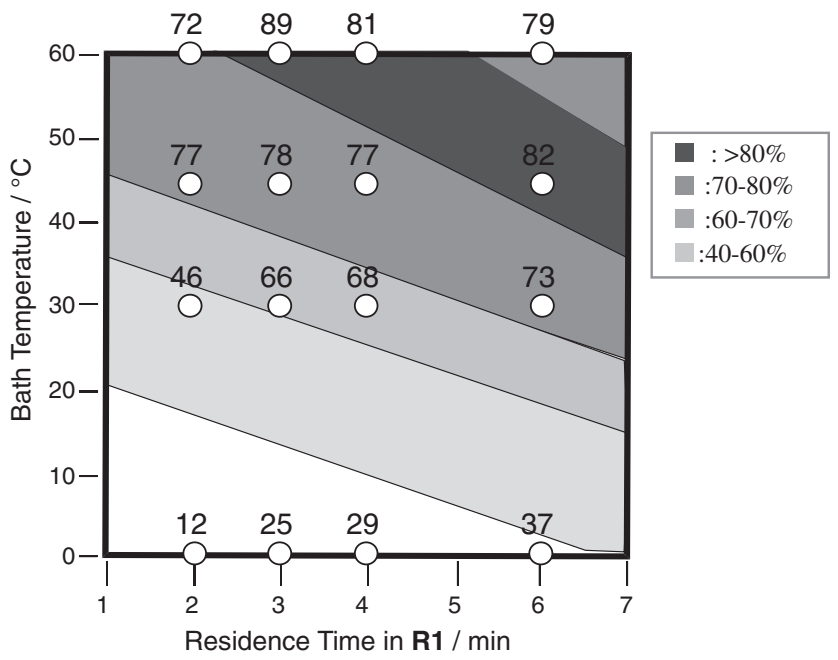

Figure 2. Effects of temperature and residence time on the yield of styrene (3a): Contour plot with scatter overlay of the yields $(\%)$.

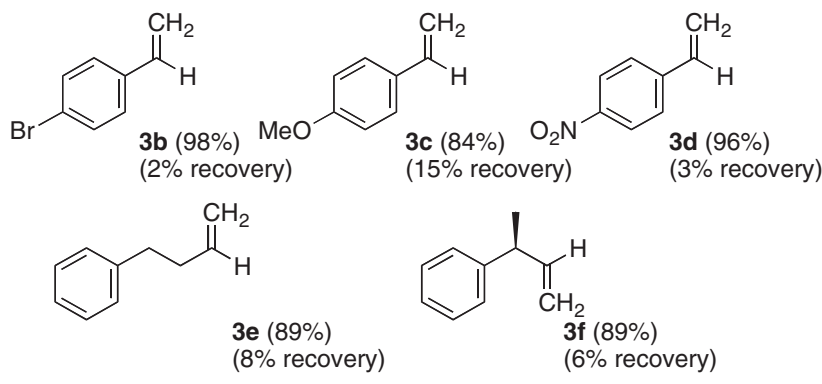

Figure 3. Yields of the methylenation products $\mathbf{3 b}-\mathbf{3 f}$ of aldehydes $\mathbf{2 b}-\mathbf{2 f}$ by the flow reactor (residence time in $\mathbf{R} \mathbf{1}$ : $3 \mathrm{~min}, 60^{\circ} \mathrm{C}$ ) in Figure 1 . The reaction gave ca. $50.8-60.0 \mathrm{mmol}$ alkene per hour. 


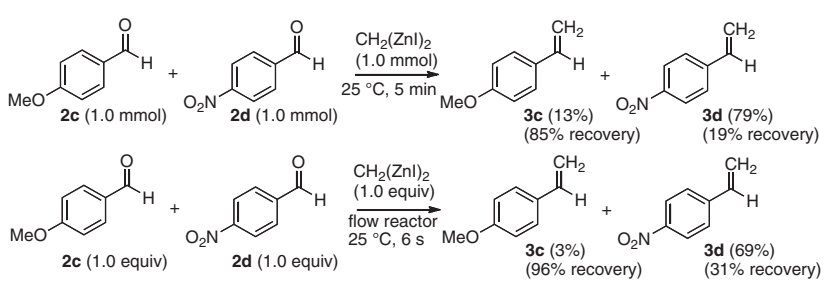

Scheme 2. Selective methylenation of a mixture of aldehydes with bis(iodozincio)methane.

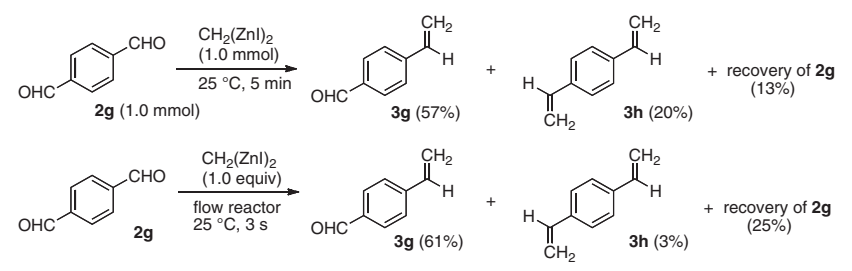

Scheme 3. Selective methylenation of dialdehyde with bis(iodozincio)methane.

formed into the corresponding styrene derivatives $\mathbf{3 b}-\mathbf{3 d}$ continuously by the flow reaction. An alkanal $2 \mathrm{e}$ was also converted into the corresponding alkene 3e. A reaction of $(R)-2-$ phenylpropanal (2f) ${ }^{6}$ with bis(iodozincio)methane (1) gave the corresponding optically active alkene, $(S)$-3-phenyl-1-butene (3f), in $89 \%$ yield without loss of optical purity. The flow reaction gives ca. $56.0 \mathrm{mmol}$ optically active alkene $3 \mathbf{f}$ per hour.

Division of two reactions in one pot by a microflow system was examined as shown in Scheme 2. While treatment of an equimolar mixture of $p$-methoxybenzaldehyde (2c) and $p$ nitrobenzaldehyde (2d) with bis(iodozincio)methane (1) in a reaction flask gave a mixture of alkenes, that in a flow reactor resulted in selective methylenation of $\mathbf{2 d}$.

More practically, transformation of 4-formylbenzaldehyde (2g) to 4-formylstyrene by flow reaction was attempted. Treatment of $\mathbf{2 g}$ with bis(iodozincio)methane (1) in a flask gave a mixture of monomethylenated product $\mathbf{3 g}$ and dimethylenated product $\mathbf{3 h}$. In the flow reactor, the monomethylenated product $\mathbf{3 g}$ was produced predominantly as shown in Scheme 3. ${ }^{7}$

It has been shown that a microflow system is efficient for integrating reactions and gives a multistep product at one burst.
Alternatively, it can divide a multistep reaction into each single reaction. Thus, a microflow system may be applied to highly selective reaction.

This work was supported by the Japanese Ministry of Education, Culture, Sports, Science and Technology.

\section{References and Notes}

1 a) J. Yoshida, A. Nagaki, T. Yamada, Chem.-Eur. J. 2008, 14, 7450. b) B. P. Mason, K. E. Price, J. L. Steinbacher, A. R. Bogdan, D. T. McQuade, Chem. Rev. 2007, 107, 2300.

2 a) S. Suga, D. Yamada, J. Yoshida, Chem. Lett. 2010, 39, 404. b) A. Nagaki, E. Takizawa, J. Yoshida, Chem. Lett. 2009, 38, 486.

3 a) M. Sada, S. Komagawa, M. Uchiyama, M. Kobata, T. Mizuno, K. Utimoto, K. Oshima, S. Matsubara, J. Am. Chem. Soc. 2010, 132, 17452. b) S. Matsubara, T. Mizuno, T. Otake, M. Kobata, K. Utimoto, K. Takai, Synlett 1998, 1369.

4 Reviews for Wittig reaction: a) A. Maercker, Org. React. 1965, 14, 270. b) B. E. Maryanoff, A. B. Reitz, Chem. Rev. 1989, 89, 863 .

5 E. Comer, M. G. Organ, J. Am. Chem. Soc. 2005, 127, 8160.

6 O. Piccolo, F. Spreafico, G. Visentin, E. Valoti, J. Org. Chem. 1985, 50, 3945.

7 Stainless steel (SUS 304) T-shaped micromixers with inner diameter $250 \mu \mathrm{m}$ were manufactured by Sanko Seiki Co., Inc. Stainless steel (SUS 316) microtube reactors with inner diameter of $1000 \mu \mathrm{m}$ was purchased from GL Science. The microflow system was dipped in a ethylene glycol bath $\left(25^{\circ} \mathrm{C}\right)$. Solutions were introduced to the microflow system using syring pumps, Harvard Model 11, equipped with gastight syringes purchased from SGE. A solution of bis(iodozincio)methane $(0.55 \mathrm{M}$ in $\mathrm{THF})$ and a solution of 4 formylbenzaldehyde $(0.55 \mathrm{M}$ in THF) was mixed (flow rate: $\left.3.9 \mathrm{~mL} \mathrm{~min}^{-1}\right)$. After the mixed solution was passed through R1 (residence time: $3.0 \mathrm{~s}$ ), the resulting mixture was poured into saturated $\mathrm{NH}_{4} \mathrm{Cl}$ aqueous solution.

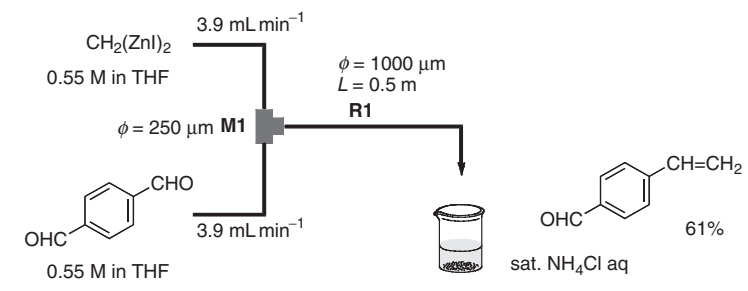

